\title{
Understanding and Promoting Effective Engagement With Digital Behavior Change Interventions
}

\author{
Lucy Yardley, $\mathrm{PhD},{ }^{1}$ Bonnie J. Spring, $\mathrm{PhD},{ }^{2}$ Heleen Riper, $\mathrm{PhD},{ }^{3}$ Leanne G. Morrison, \\ PhD, ${ }^{1}$ David H. Crane, MSc, ${ }^{4}$ Kristina Curtis, $\mathrm{PhD},{ }^{5}$ Gina C. Merchant, $\mathrm{PhD},{ }^{6}$ Felix \\ Naughton, $\mathrm{PhD},{ }^{7}$ Ann Blandford, $\mathrm{PhD}^{8}$
}

\begin{abstract}
This paper is one in a series developed through a process of expert consensus to provide an overview of questions of current importance in research into engagement with digital behavior change interventions, identifying guidance based on research to date and priority topics for future research. The first part of this paper critically reflects on current approaches to conceptualizing and measuring engagement. Next, issues relevant to promoting effective engagement are discussed, including how best to tailor to individual needs and combine digital and human support. A key conclusion with regard to conceptualizing engagement is that it is important to understand the relationship between engagement with the digital intervention and the desired behavior change. This paper argues that it may be more valuable to establish and promote "effective engagement," rather than simply more engagement, with "effective engagement" defined empirically as sufficient engagement with the intervention to achieve intended outcomes. Appraisal of the value and limitations of methods of assessing different aspects of engagement highlights the need to identify valid and efficient combinations of measures to develop and test multidimensional models of engagement. The final section of the paper reflects on how interventions can be designed to fit the user and their specific needs and context. Despite many unresolved questions posed by novel and rapidly changing technologies, there is widespread consensus that successful intervention design demands a user-centered and iterative approach to development, using mixed methods and in-depth qualitative research to progressively refine the intervention to meet user requirements.
\end{abstract}

\section{Introduction}

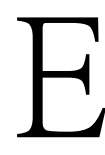

ngagement with health interventions is a precon- dition for effectiveness; this is a particular concern for digital behavior change interventions (DBCIs),

From the ${ }^{1}$ Department of Psychology, University of Southampton, South- ampton, United Kingdom; ${ }^{2}$ Feinberg School of Medicine, Northwestern University, Chicago, Illinois; ${ }^{3}$ Department of Clinical Psychology, VU University Amsterdam, Amsterdam, Netherlands; ${ }^{4}$ Research Department of Clinical, Education and Health Psychology, University College London, London, United Kingdom; ${ }^{5}$ Centre for Technology Enabled Health Research, Coventry University, Coventry, United Kingdom; ${ }^{6}$ Department of Family Medicine and Public Health, University of California, San Diego, California; ${ }^{7}$ Department of Public Health and Primary Care, University of Cambridge, Cambridge, United Kingdom; and ${ }^{8}$ Institute of Digital Health, University College London, London, United Kingdom

Address correspondence to: Lucy Yardley, PhD, Department of Psychology, University of Southampton, Highfield, Southampton, SO17 1BJ, United Kingdom. E-mail: 1.yardley@ soton.ac.uk. that is, interventions that employ digital technologies such as the Internet, telephones, and mobile and environmental sensors. ${ }^{1}$ Maintaining engagement can be especially diffi- cult when DBCIs are used without human support, typically leading to high levels of dropout and "non-usage attrition,", whereby participants do not sustain engage- ment with the intervention technologies. This paper discusses current approaches to conceptualizing and measuring engagement, and considers key issues relevant to promoting effective engagement.

This paper is one in a series developed through a process of expert consensus to provide an overview of questions of current importance in research into engage- ment with DBCIs, and to identify outstanding conceptual and methodologic issues. ${ }^{1}$ An international steering committee invited established and emerging experts to form a writing group to contribute to this process. The scope, focus, and conclusions were formulated initially by the committee and writing group, and then further discussed and modified with input from 42 experts contributing to a multidisciplinary international 
workshop. As such, the paper is necessarily selective and does not exhaustively review the relevant literature or propose particular models or solutions, but provides a critical reflection on the state of the art. The insights gained from this process are summarized in the con- cluding table as guidance based on research to date and priority topics for future research.

Some of the insights into engagement that emerged are specific to DBCIs, which have features that are not shared with other forms of intervention delivery - in particular, the potential to automatically record and respond to how the user is engaging with the intervention. However, many of the challenges confronting DBCI use are shared with other types of intervention-for example, the need for users to engage with the behavior change. Conse- quently, the unique potential of DBCIs to record engage- ment and behavior in detail over time is likely to generate important new insights that have relevance to engage- ment with other behavior change interventions.

\section{Understanding Engagement}

\section{Conceptualizing Engagement}

The term engagement has been used in different ways in engagement research, making it challenging to synthesize the models and measures that have been proposed. Some researchers focus principally on engagement with digital technology, drawing on disciplines such as human- computer interaction, psychology, communication, mar- keting, and gamebased learning. ${ }^{4}$ In this approach, engagement is typically studied in terms of intervention usability and usage, and factors that influence these. For example, $\mathrm{O}^{\text {'Brien and Toms }}{ }^{5}$ define engagement as a quality of users' experiences with technology; they identify dimensions of challenge, aesthetic and sensory appeal, feedback, novelty, interactivity, perceived control and time, awareness, motivation, interest, and affect.
Other researchers approach DBCIs as a specific method of delivering health interventions, viewing engagement with DBCIs as similar to engagement with face-to-face interventions. This approach focuses on users' engage- ment with the process of achieving positive cognitive, emotional, behavioral, and physiologic change. It draws on evidence-based therapeutic principles (such as cognitive-behavioral therapy); existing behavioral theo- ries (such as social cognitive models); and research on broader engagement processes (such as the therapeutic alliance and social support). For example, key design features of DBCIs identified by Morrison et al. ${ }^{6}$ include social context and support, contacts with the interven- tion, tailoring, and self-management.

To understand and analyze the relationship between engagement with technology and behavior change, it may be helpful to distinguish between the "micro" level of moment-to-moment engagement with the intervention and the "macro" level of engagement and identification with the wider intervention goals, while appreciating that these are intimately linked. Figure 1 illustrates how engagement with the DBCI and the behavioral goals of the intervention may vary over time. Engagement is a dynamic process that typically starts with a trigger (e.g., recommendation by health professional or peers), fol- lowed by initial use, which may be followed by sustained engagement, disengagement, or shifting to a different intervention. The timing of and relationship between the different forms of engagement will vary depending on the intervention, the user, and their context.

Some engagement models attempt to encompass the full range of factors that may influence engagement with both the digital technology and the health-related behav- ior change. For example, the Behavioral Intervention Technology model $^{7}$ builds on and integrates several other relevant models, ${ }^{8-11}$ providing a framework for articulat- ing the relationship among the behavioral intervention

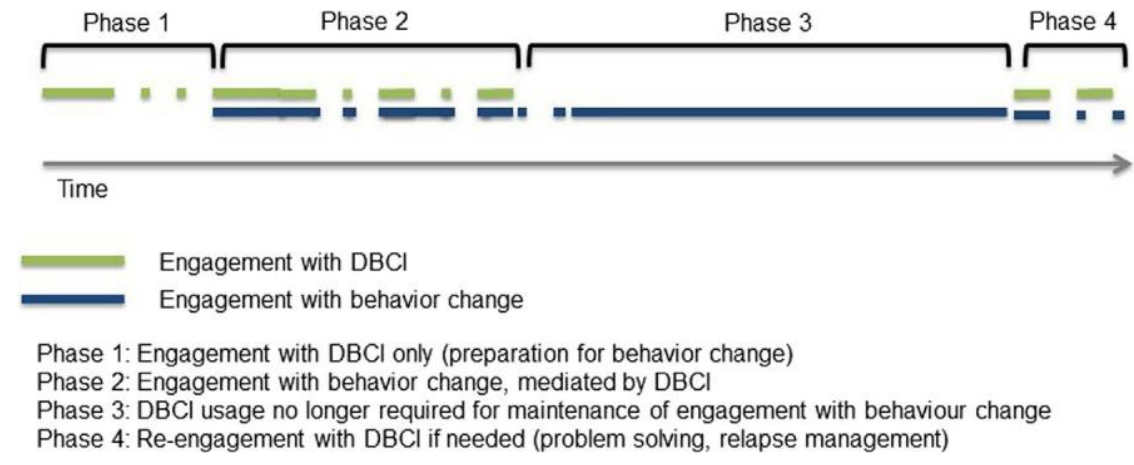

Figure 1. Illustration of the "micro" and "macro" levels of intervention engagement. Note: This hypothetical example illustrates one way in which engagement with the technology and the behavior change could vary over time; patterns of engagement will vary widely with different interventions and individuals.

DBCI, digital behavior change intervention. 
aims, elements, characteristics, and workflow and the technologic methods of implementing the intervention. New interdisciplinary models of engagement are emerg- ing but are largely untested; consequently, their validity is not yet established. Some authors have used literature review to identify retrospectively which factors are associated with success of DBCIs, ${ }^{6,12-14}$ but the strength of the conclusions that can be drawn is limited by the correlational nature of the evidence and incomplete descriptions of the interventions. Establishing which elements of these models are most influential on engage- ment is therefore a key research priority, and new theoretic frameworks and models may need to be developed (as discussed elsewhere in this issue). ${ }^{15}$ Taxonomies of features specific to DBCIs (such as digital delivery meth- ods ${ }^{10}$ ) may prove useful for this purpose; for example, taxonomies have helped to clarify what types of supple- mentary support are associated with positive DBCI out- comes, ${ }^{16}$ what features of computerized clinical decision support systems are effective,${ }^{17}$ and the importance of feedback in weight management DBCIs. ${ }^{18}$

User engagement is also supported, undermined, or shaped by socio-contextual influences, such as the role played by family members and the broader cultural setting. Comprehensive models of engagement need to encompass not only individuallevel user dimensions but also the effects-positive and negative - of social dimen- sions. For example, technologies can harness social support by sharing behavioral tracking and promoting encouragement from peers, ${ }^{19}$ but some users may be less likely to commit to behavioral goals if they will be publicly shared. ${ }^{20}$

A crucial implication of explicitly recognizing the distinction between engagement with the technologic and behavioral aspects of the intervention is that intervention usage alone cannot be taken as a valid indicator of engagement. In the absence of agreed definitions and well-validated theoretic models of engagement, much previous research has operationalized engagement as the extent to which people use the digital intervention as intended, ${ }^{13}$ on the assumption that usage is closely related to outcome. There are several problems with this assumption. First, the evidence that usage is associated with intended outcomes is mixed, and largely correlational. ${ }^{21-23}$ It is difficult to determine to what extent usage mediates behavioral and healthrelated outcomes, as this may be confounded by common factors such as higher motivation and selfregulation skills. Usage metrics also reveal little about offline engagement with intervention content, which is important in inter- ventions that require homework outside the context of the digital intervention. A further complication is that cessation of usage could indicate disengagement from an intervention, or could signal sufficient mastery that continued access to the digital technology is no longer needed (Figure 1). Continued engagement might indicate positive, healthy engagement with the intervention con- tent or, conversely, dependence on the guidance or feedback, and thus a lack of successful self-regulation. Rather than focus on "engagement," it would be benefi- cial to focus on "effective" engagement that mediates positive outcomes; this may or may not require sustained engagement. Effective engagement is thus defined in relation to the purpose of a particular intervention, and can only be established empirically, in the context of that intervention. A further consideration is that users may value different outcomes from those intended by design- ers ${ }^{24}$; for example, a DBCI may not achieve behavior change but may provide valued information, reassurance, or opportunities for interaction.

In summary, a key research challenge is to conceptu- alize engagement more consistently, comprehensively, and dynamically, taking into account user experiences of the technology and the social and therapeutic context. The next step is not simply to propose but to test and validate models of effective engagement by demonstrat- ing which elements of these models positively influence different aspects of engagement and mediate outcomes. The following section explains how the multidimensional nature of effective engagement can be captured by using complementary methods of assessment.

\section{Evaluating Engagement}

A range of methods is available to measure effective engagement (Table 1) that offer complementary insights into different dimensions of engagement, and can be used at different stages of intervention development, evaluation, and implementation. These include reports of the subjective user experience, elicited by qualitative methods or questionnaires, and objective measures of technology usage, user behavior, and users' reactions to the intervention.

In-depth qualitative analyses of user experiences can capture critical information about how a user reacts to the content and design of DBCIs and offer explanations for why the user interacts with a DBCI in particular ways. These data enable researchers to explain objective usage patterns more reliably and generate hypotheses about the factors influencing effective engagement that can be tested using other methods. Qualitative analyses can capture critical information about offline behavior (particularly engagement with the behavioral target of the intervention) and the wider social and contextual influences on engagement. ${ }^{25}$ Qualitative methods can also reveal aspects of engagement with the technology that may not be 
Table 1. Value of and Considerations for Using Different Methods of Measuring Engagement With DBCIs

\begin{tabular}{|c|c|c|}
\hline Measure & Value & Considerations \\
\hline $\begin{array}{l}\text { Qualitative analysis of self-report } \\
\text { data (optionally complemented by } \\
\text { observational data) }\end{array}$ & $\begin{array}{l}\text { Provide an in-depth interpretive account of the } \\
\text { individual's perceptions and experiences of using a } \\
\text { DBCI and engaging with DBCI content (both on- and } \\
\text { off- line) } \\
\text { Can assess values and context } \\
\text { Useful for theory and hypothesis generation }\end{array}$ & $\begin{array}{l}\text { Subject to reporting biases, e.g., recall } \\
\text { bias (if retrospective) and socially } \\
\text { desirable responding } \\
\text { Individuals not always aware of their } \\
\text { motives and behavior } \\
\text { Intrusive, time consuming to collect } \\
\text { and analyze-so generally small, } \\
\text { atypical samples of users }\end{array}$ \\
\hline Self-report questionnaires & $\begin{array}{l}\text { Allow assessment of subjective perceptions of large } \\
\text { samples of users } \\
\text { Standardized questionnaires enable comparisons } \\
\text { across studies } \\
\text { Convenient, can be administered online } \\
\text { Can be validated, e.g., by relationship to objective } \\
\text { measures and outcomes }\end{array}$ & $\begin{array}{l}\text { Subject to reporting biases } \\
\text { (see above) } \\
\text { May lack depth } \\
\text { Individuals not always aware of } \\
\text { their motives and behavior } \\
\text { Intrusive, can be high response } \\
\text { burden (if many aspects of } \\
\text { engagement assessed) } \\
\text { Validity not yet established }\end{array}$ \\
\hline $\begin{array}{l}\text { Ecological Momentary Assessment } \\
\text { (EMA) }\end{array}$ & $\begin{array}{l}\text { Captures experience in the moment } \\
\text { Less prone to recall bias }\end{array}$ & $\begin{array}{l}\text { May disrupt engagement and become } \\
\text { an additional intervention } \\
\text { High response burden and } \\
\text { intrusiveness, leading to missing data }\end{array}$ \\
\hline $\begin{array}{l}\text { Log(s) of system usage data (e.g., } \\
\text { time spent on DBCI, number and } \\
\text { type of pages visited) }\end{array}$ & $\begin{array}{l}\text { Reliable measure of physical use of DBCI } \\
\text { Analysis can identify usage patterns associated with } \\
\text { better outcomes }\end{array}$ & $\begin{array}{l}\text { Does not measure engagement } \\
\text { with behavior change } \\
\text { Often difficult to interpret usage } \\
\text { patterns }\end{array}$ \\
\hline $\begin{array}{l}\text { Smartphone, mobile, and } \\
\text { environmental sensors }\end{array}$ & $\begin{array}{l}\text { Can automatically collect data on user behavior and } \\
\text { context and so have high ecological validity }\end{array}$ & $\begin{array}{l}\text { Often low sensitivity and reliability } \\
\text { Practical and ethical barriers to be } \\
\text { overcome (e.g., smartphone battery } \\
\text { drain, identifying data) }\end{array}$ \\
\hline $\begin{array}{l}\text { Psychophysiological measures } \\
\text { (e.g., fMRI, gaze tracking) }\end{array}$ & $\begin{array}{l}\text { Objective measures of arousal and visual attention } \\
\text { Can measure automatic responses and attitudes toward } \\
\text { DBCI outside of individual's awareness }\end{array}$ & $\begin{array}{l}\text { May be difficult to interpret (e.g., if } \\
\text { contradict self-report) as may not be } \\
\text { accurate and reliable } \\
\text { Often intrusive, expensive-not } \\
\text { scalable } \\
\text { Laboratory-based measures may lack } \\
\text { ecological validity }\end{array}$ \\
\hline
\end{tabular}

DBCI, digital behavior change intervention; fMRI, functional magnetic resonance imaging.

captured by quantitative usage data - such as "lurking," a common phenomenon whereby users read and may benefit from the content in online social communities but do not actively interact with the digital intervention. ${ }^{26,27}$ Typical qualitative methods include focus groups; interviews; observation of user interaction with the inter- vention (which might include users "thinking aloud" while using the intervention); diary studies; and retrospective interviews. ${ }^{28}$ Given the increasing reliance on participant involvement in DBCI design, it is vital that research clarifies what users are able to report accurately. For example, users can usually identify aspects of a DBCI that they dislike or describe their views and behavior, but few users can prospectively anticipate factors that will encour- age effective engagement with DBCI content or retros- pectively recall their reasons for engagement or disengagement.
Self-report questionnaires can also measure dimensions of engagement (including offline engagement) that cannot be assessed objectively. Questionnaires to retrospectively assess engagement with DBCIs at selected time points are available. ${ }^{29}$ Alternatively, ecologic momentary assessment enables immediate, repeated measurement of users' experiences with interventions in the moment. ${ }^{30} \mathrm{~A}$ dilemma for self-reporting is to balance the need to measure all relevant dimensions of engagement with the response burden for users, which may also lead to measurement effects such as response shift and be an intervention in itself. Although a solution may be to develop validated instruments to measure engagement within a specific setting, the use of different questionnaires for each study would limit cross-study comparisons. Further research is also required to establish the validity of questionnaires assessing engagement in terms of predicting outcomes. 
Qualitative insights and questionnaire data can be complemented by proxy measures of engagement based on usage. ${ }^{31}$ These can include the number of visits/uses, modules or features used, time spent on the intervention, number and type of pages visited, or response to alerts or reminders. ${ }^{32}$ Usage metrics can provide valuable insights, but are typically large, complex data sets that are challenging to interpret. For example, additional qual- itative data can be needed to provide explanations for observed differences in usage metrics between partici- pants or intervention groups. ${ }^{33}$ Recent advances in sequence analysis, data mining, and novel visualization tools are facilitating analyses of usage patterns, and there is scope for substantial progress in this field. ${ }^{23}$ DBCIs have the potential to generate data sets sufficiently large to be able to reliably model and experimentally test $^{34}$ mediation of outcomes by engagement with particular intervention components and to statistically control for confounding moderator effects such as baseline motiva- tion levels. ${ }^{22,26,35,36}$ Importantly, usage metrics can be collated with data on users' behavior collected by smartphone sensors, such as movement or location. ${ }^{37}$ However, more studies are needed to establish what features or correlates of engagement sensor data can capture reliably, and new statistical approaches will be required to analyze these large and complex data sets. The novel research designs that can support these analyses are discussed in companion papers in this issue. ${ }^{15,34,38}$

Psychophysiological measurements, ranging from skin conductance and heart rate to facial expression or fMRI, have been used to measure users' task engagement. ${ }^{39}$ Such measures can help identify aspects of the inter- vention that attract attention or evoke emotional arousal, suggesting mechanisms through which DBCI content or design impact shortterm engagement. These surrogate measures of engagement can be difficult to interpret, and differences in attention may not always translate into differences in intervention use (or other measures of engagement). ${ }^{40}$ That said, they do complement subjective measures by providing an objective measure of user reactions.

To summarize, effective engagement can only be understood through valid, reliable, and comprehensive means of assessment. Adopting a mixed method multi- dimensional approach will provide a more comprehen- sive picture of how (well) users are engaging with DBCIs, ${ }^{41}$ but can pose problems of resource constraints and user burden, particularly when interventions are implemented "in the wild." The complementary value of different approaches for understanding effective engage- ment remains to be clarified; further work is needed to determine the most accurate and efficient combinations of assessments, and to understand better how to compare and integrate the data, inferences, and outcome relation- ships derived from complementary measures that tap into different aspects of engagement.

\section{Promoting Effective Engagement}

This section first introduces techniques for promoting effective engagement, identifying substantive gaps in knowledge and directions for future investigation, and then considers two key topics in engagement research: tailoring to individual needs (including the needs of those with lower levels of literacy and computer literacy) and combining DBCIs with human support.

\section{Developing Engaging Digital Behavior Change} Interventions

Promoting effective engagement requires interventions to be perceived as having benefits that outweigh their costs - including the "opportunity costs" of engaging in other valued activities. The benefits can be affective or functional, meaning that DBCIs may be valued because they create an intrinsically enjoyable user experience (such as health-promoting games) or because they are seen as meeting evidence-based therapeutic principles and users' needs (such as online cognitive-behavioral therapy). In the latter case, users may engage even if they are not enjoyable. To fully appreciate users' needs and perspectives, it is essential to involve the target popula- tion in intervention development.

Structured methods to guide intervention development that emphasize the importance of engaging end users have been developed. The aim of user-centered design is to ground the development of all digital products in an understanding of the user's knowledge, skills, behavior, motivations, culture, and context. ${ }^{42}$ The "person-based approach" to digital health intervention development ${ }^{43}$ provides a complementary health-related behavioral science focus, emphasizing user views of the behavior change techniques the intervention is intended to support, both online and offline. There is considerable convergence in views of the process needed to achieve high-quality DBCIs. An iterative development and eval- uation process, with repeated use of applied methods to engage stakeholders, is needed to progressively refine the intervention to meet user requirements; hence, qualita- tive methods are central to understanding how to improve user engagement with the technology and the behavior change.

To date, engagement research has tended to be pragmatic, focusing on addressing the specific engagementrelated issues arising in the context of a particular intervention. The field could benefit from more systematic 
attention to methodologic issues; for example, the preced- ing discussion suggests it may be more fruitful to focus on promoting effective rather than sustained engagement. An additional challenge is that different forms of technology are engaged with in different ways. For example, the portability of smartphones and wearables offers exciting opportunities for "just-intime" interventions, but those interventions are likely to be used in distracting environ- ments, for brief periods, using small screens and keyboards. Methods of achieving effective engagement need to be developed to accommodate the various technologies used and where and when they are used. Consideration also needs to be given to how best to combine the iterative qualitative process of refining engagement with new, quantitative methods of evaluating the effectiveness of DBCI ingredients. ${ }^{35,39}$

\section{Tailoring and Fit}

Engagement with DBCIs has typically been greater among those with higher levels of education and income. ${ }^{3}$ However, recent improvements in digital access in lower-income countries and to all sociodemographic groups mean that it is timely and

important to consider the extent to which it may be necessary to tailor DBCIs to ensure they are accessible and engaging for people with lower levels of education, literacy, or computer literacy. ${ }^{44}$

Interventions to improve health literacy have included using simple language, presenting information in audio- visual formats, tailoring content to individual needs, and other forms of interactivity. ${ }^{45-47}$ These approaches have shown

promise for improving knowledge and selfmanagement, but the evidence is inconclusive, few studies have been theory-based, and it remains unclear whether different intervention elements engage and optimize outcomes for people at varying levels of health literacy. ${ }^{48}$ There is some evidence that intervention design formats that are accessible and engaging for people with lower levels of health literacy may also be acceptable and usable by people with higher levels. ${ }^{49}$ If confirmed, those findings suggest that DBCIs for all can be designed to be accessible and engaging for those with low health

literacy. Involving people from lower-income backgrounds in research poses challenges that need to be overcome to better understand their needs and barriers. Further research is also needed to understand how to design interventions to support people with particular attributes. Market segmentation informs most product design, but the "market" for DBCIs is relatively imma- ture, and understanding of the

factors that influence engagement with DBCIs is correspondingly immature. Factors likely to shape people's engagement with DBCIs include their lifestyles and what interests and motivates them. For example, an intervention to help an individual with mobility difficulties who is frightened of causing injury and pain will look and feel different from one designed for an injured athlete wanting to get back to full fitness. Within any market segment, there is then scope for allowing users to tailor the intervention to their particular situation and requirements. Moreover, adap- tive interventions should permit tailoring for individual differences to be supplemented by "within-person" tailoring as the individual's needs and status change. ${ }^{15}$ Context sensing (using mobile or environmental sensors to detect features of the person's current behavior and circumstances) should enable timely delivery of content and notifications tailored to the individual's immediate situation $^{50}$; for example, activity sensors have been used successfully to detect sedentary behavior and prompt physical activity breaks. Although context sensing should increase engagement by enhancing the perceived attune- ment of the intervention, limited research has yet examined this assumption owing to the novelty of this technology. ${ }^{51}$

Tailoring digital intervention delivery and content to users' needs, motivations, and personal characteristics enables users to receive guidance that is appropriate, relevant, and safe for them. Tailoring can have a positive impact on intervention outcomes and engagement, but this varies between studies and contexts. ${ }^{31,52}$ Self- determination theory ${ }^{53}$ a prominent theory of motivation, argues that autonomy is a fundamental human need that facilitates learning. Hence, fostering autonomy by giving users personal choices throughout an intervention should be motivating. ${ }^{54}$ A major benefit of digitally delivered interventions is the possibility of offering recipients a choice of formats and tools, allowing users to "selftailor," selecting what they find most accessible, attractive, and useful. Nevertheless, conventional tailoring of content to match an individual's demographic characteristics ${ }^{55,56}$ may still be required to ensure that users are not presented with material they find so alienating or demotivating that they abruptly cease using the intervention. In summary, tailoring can be valuable, but the optimal balance between tailoring and self-tailoring in different contexts requires further investigation.

\section{Combining Digital and Human Support}

Adding human facilitation can improve effective engage- ment with DBCIs, but there is considerable heterogeneity in findings; few studies directly contrast different levels of support, and comparing across studies is problematic. $^{57-61}$ Moreover, unguided interventions can also be effective, although effect sizes are usually smaller. It is important to establish when human support adds value, as unguided 
interventions can be disseminated more easily at lower cost and could therefore have huge impact at a population health level.

Variations in findings regarding benefits of human facilitation may reflect different health needs and pref- erences of users that, in turn, may vary depending on the types of intervention and facilitation offered. ${ }^{62}$ Simple interventions that users are confident to implement without support may not benefit from additional facili- tation. ${ }^{63}$ Human facilitation may be more important when users feel the need for an expert to reassure, guide, or emotionally support them, or hold them accountable. The need for human facilitation may diminish for certain conditions as interventions incorporate elements that make them increasingly user friendly, adaptive, persua- sive, even enjoyable, or able to reproduce the required elements of a therapeutic relationship. Further research is needed to identify what features diminish the need for human involvement in delivering DBCIs.

The "supportive accountability" conveyed by having a benevolent but expert human coach maintain surveil- lance of the participant's interactions is usually valuable to maintain motivation and adherence to intervention requirements. ${ }^{64}$ Human facilitation by peer counselors may help as well, creating a supportive community and affirming that the intervention has been found relevant and feasible by others facing similar health problems. However, integrating DBCIs with health care delivered in person can be challenging. Too often, the development of DBCIs has been carried out without the involvement of clinicians or attention to how the digital intervention may impact the health professional's activities, roles, and interactions with patients. To maximize clinician engage- ment, clinicians should be confident that the intervention extends and complements their ability to provide effi- cient and effective care. $^{65}$ Few studies have taken a holistic approach toward designing for service delivery, in addition to designing for the individual recipient of the intervention. There is an urgent need for techniques to co-design DBCIs so that they reengineer clinician- patient-family interactions to improve engagement.

A final topic requiring more investigation concerns the optimal format to integrate human facilitation with digital interventions. Clinician referral to a DBCI enhan- ces engagement, compared with interventions being simply made freely available over the Internet or as apps ${ }^{66}$; this suggests that positive endorsement and follow-up by a familiar health professional promotes trust in the intervention. However, remote (telephone, e-mail, or text) coaching to help the user implement the intervention can also be effective, ${ }^{67}$ even without the referral or endorsement of a clinician. This model of provision makes it feasible and cost effective to offer skilled support by facilitators who have experience of working with the digital intervention. In summary, further research is needed to understand better the nature, timing, and extent of support required in differ- ent intervention contexts.

\section{Conclusions}

Significant progress has been made in recent years in understanding the nature of and requirements for engagement, and particularly in recognizing the impor- tance of carrying out in-depth mixed methods research into how people engage with DBCIs. Table 2 summarizes key guidance points emerging from research to date and highlights areas for further work. Future research would benefit from defining engagement more consistently and appropriately, appreciating that more engagement does not necessarily equate to more effective engagement. Research priorities include empirically testing models of

Table 2. Key Guidance Points and Priority Topics for Future Research

Guidance points based on existing research

- To fully understand and address issues affecting user engagement, carry out iterative, in-depth mixed methods research with a broad spectrum of users as well as involving user panels in the research process

- Employ multiple measures of engagement, while minimizing user burden and measurement effects as far as possible

- Specify and establish empirically for each intervention what constitutes "effective engagement,"i.e., engagement that is associated with positive intervention outcomes

Priority topics for future research

- Further develop and test taxonomies and models of engagement, considering how technological and behavioral elements combine to influence effective engagement

- Investigate and validate complementary and non-intrusive measures of effective engagement and novel methods of analyzing and triangulating qualitative and quantitative data

- Examine further when and how to tailor interventions to address individual and contextual needs

- Establish how best to implement DBCIs in the future, using new forms of delivery, and ensuring they are accessible to those with lower levels of education or income 
how technologic and behavioral elements combine to influence effective engagement, using engagementrelated taxonomies to accumulate knowledge and iden- tify mechanisms of action. Comprehensive model testing will require developing and validating complementary objective and subjective measures of engagement, includ- ing non-intrusive methods that can be easily imple- mented without creating user burden or reactivity. Using these models and measures, researchers will then be able to tackle important questions relating to the implemen- tation of DBCIs, such as how best to involve users, developers, healthcare professionals, and family in co- design; how to utilize new forms of delivery; how to design interventions that are accessible to those with lower levels of education or income; and when and how interventions need to be adapted for the individual or supplemented by human support.

\section{Chronic}

This 2016 theme issue of the American Journal of Preventive Medicine is supported by funding from the NIH Office of Behavioral and Social Sciences Research (OBSSR) to support the dissemination of research on digital health interventions, methods, and implications for preventive medicine.

This paper is one of the outputs of two workshops, one supported by the Medical Research Council (MRC)/National Institute for Health Research (NIHR) Methodology Research Program (PI Susan Michie), the OBSSR (William Riley, Director), and the Robert Wood Johnson Foundation (PI Kevin Patrick); and the other by the National Science Founda- tion (PI Donna Spruitj-Metz, proposal \# 1539846).

No financial disclosures were reported by the authors of this paper.

\section{References}

1. Yardley L, Patrick K, Choudhury T, Michie S. Current issues and future directions for digital intervention research. Am J Prev Med. 2016.

2. Eysenbach G. The law of attrition. J Med Internet Res. 2005;7:e11. http: //dx.doi.org/10.2196/jmir.7.1.e11.

3. Kohl LFM, Crutzen R, de Vries N. Online prevention aimed at lifestyle behaviours: a systematic review of reviews. J Med Internet Res.2013;7: e146. http://dx.doi.org/10.2196/jmir.2665.

4. Bouvier P, Lavoue E, Sehaba K. Defining engagement and character- izing engaged-behaviors in digital gaming. Simul Gaming. $\quad 2014$; 45(4-5):491-507. http://dx.doi.org/10.1177/1046878114553571.

5. O'Brien HL, Toms EG. What is user engagement? A conceptual framework for defining user engagement with technology. J Assoc Inf Sci Technol. 2008;59(6):938-955. http://dx.doi.org/10.1002/asi.20801.

6. Morrison LG, Yardley L, Powell J, Michie S. What design features are
8. Fogg B. A behavior model for persuasive design. Proceedings of the 4th International Conference on Persuasive Technology. 2009:40. http://dx. doi.org/10.1145/1541948.1541999.

9. Oinas-Kukkonen H, Harjumaa M. Persuasive system design: key issues, process model, and system features. Commun Assoc Inf Syst. 2009;24(28):485-500.

10. Ritterband LM, Thorndike FP, Cox DJ, Kovatchev BP, Gonder-

Frederick LA. A behavior change model for Internet interventions. Ann Behav Med. 2009;38(1):18-27. http://dx.doi.org/10.1007/ s12160-009-9133-4.

11. Crutzen R. The behavioral intervention technology model and

intervention mapping: the best of both worlds. J Med Internet Res. 2014;16(8):e188. http://dx.doi.org/10.2196/jmir.3620.

12. Cugelman B, Thelwall M, Dawes P. Online interventions for social

marketing health behavior change campaigns: a meta-analysis of psychological architectures and adherence factors. J Med Internet Res. 2011;13(1):e17. http://dx.doi.org/10.2196/jmir.1367.

13. Kelders SM, Kok RN, Ossebaard HC, Van Gemert-Pijnen JE. Persua-

sive system design does matter: a systematic review of adherence to web-based interventions. J Med Internet Res. 2012;14(6):e152. http:

//dx.doi.org/10.2196/jmir.2104.

14. Schubart JR, Stuckey HL, Ganeshamoorthy A, Sciamanna CN.

used in effective e-health interventions? A review using techniques from critical interpretive synthesis. Telemed JE Health. 2012;18(2):19. http://dx.doi.org/10.1089/tmj.2011.0062.

7. Mohr DC, Schueller SM, Montague E, Burns MN, Rashidi P. The behavioral intervention technology model: an integrated conceptual and technological framework for eHealth and mHealth Interventions. J Med Internet Res. 2014;16(6):e146. http://dx.doi.org/10.2196/jmir.3077. 
health conditions and Internet behavioral interventions: a review of factors to enhance user engagement. Comput Inform Nurs. $2011 ; 29$

(2):81-92.

http://dx.doi.org/10.1097/NCN.0b013e3182155274.

15. Hekler EB, Michie S, Rivera, et al. Developing and refining models and theories suitable for digital health interventions. Am J Prev Med. 2016.

16. Webb TL, Joseph J, Yardley L, Michie S. Using the Internet to promote health behavior change: a systematic review and metaanalysis of the impact of theoretical basis, use of behavior change techniques, and mode of delivery on efficacy. J Med Internet Res. 2010;12(1):e4. http: //dx.doi.org/10.2196/jmir.1376.

17. Roshanov PS, Fernandes N, Wilczynski JM, et al. Features of effective computerized clinical decision support systems: metaregression of 162 randomized trials. BMJ. 2013:346. http://dx.doi.org/10.1136/bmj.f657.

18. Sherrington A, Newham JJ, Bell R, et al. Systematic review and meta-

analysis of Internet-delivered interventions providing personalized feedback for weight loss in overweight and obese adults. Obes Rev. 2016;17(6):541-551. http://dx.doi.org/10.1111/obr/12396.

19. Maher CA, Lewis LK, Ferrar K, et al. Are health behavior change interventions that use online social networks effective? A systematic review. J Med Internet Res. 2014;16(2):e40. http://dx.doi.org/10.2196/ jmir.2952.

20. Munson SA, Krupka E, Richardson C, Resnick P. Effects of public

commitments and accountability in a technology-supported physical activity intervention. Proceedings of the 33rd Annual ACM Conference on Human Factors in Computing Systems. 2015:11351144. http://dx. doi.org/10.1145/2702123.2702524.

21. Danaher BG, Seeley JR. Methodological issues in research on web- based behavioral interventions. Ann Behav Med. 2009;38(1):28-39. http://dx.doi.org/10.1007/s12160-0099129-0.

22. Strecher VJ, McClure J, Alexander G, et al. The role of engagement in a tailored web-based smoking cessation program: randomized controlled trial. J Med Internet Res. 2008;10(5):e36. http://dx.doi.org/10.2196/ jmir.1002.

23. Van Gemert-Pijnen JE, Kelders SM, Bohlmeijer ET. Understanding the usage of content in a mental health intervention for depression: an analysis of log data. J Med Internet Res. 2014;16(1):e27. http://dx.doi. org/10.2196/jmir.2991.

24. Schneider H, Moser K, Butz A, Alt F. Understanding the mechanics of

persuasive system design: a mixed-method theory-driven analysis of freeletics. Proceedings of the 2016 CHI Conference on Human Factors in Computing Systems. 2016:309-320. http://dx.doi.org/10.1145/2858036. 2858290. 
25. Laurie J, Blandford A. Making time for mindfulness. Int J Med Inform. In press. Online March 2, 2016. http://dx.doi.org/10.1016/j.ijmedinf. 2016.02.010.

26. Graham AL, Papandonatos GD, Erar B, Standton CA. Use of an online

smoking cessation community promotes abstinence: results of pro- pensity score weighting. Health Psychol. 2015;34:1286-1295. http://dx. doi.org/10.1037/hea0000278.

27. Sun N, Rau PP-L, Ma L. Understanding lurkers in online communities:

a literature review. Comput Human Behav. 2014;38:110-117. http://dx. doi.org/10.1016/j.chb.2014.05.022.

28. Blandford A. Semi-structured qualitative studies. In: Soegaard M, Dam

RF, eds. The Encyclopedia of Human-Computer Interaction. 3rd ed. Aarhus, Denmark: The Interaction Design Foundation, 2014. www. interaction-design.org/encyclopedia/semistructured_qualitative_stu dies.html. Accessed November 5, 2015.

29. Lefebvre CR, Tada Y, Hilfiker SW, Baur C. The assessment of user engagement with eHealth content: the eHealth engagement scale. $\quad J$ Comput Commun. 2010;15(4):666-681. http://dx.doi.org/10.1111/ j.1083-6101.2009.01514.x.

30. Warmerdam L, Riper H, Klein M, et al. Innovative ICT solutions to

improve treatment outcomes for depression: the ICT4Depression project. Stud Health Technol Inform. 2012;181:339-343. http://dx.doi. org/10.3233/978-1-61499-121-2-339.

31. McClure JB, Shortreed SM, Bogart A, et al. The effect of program design on engagement with an Internet-based smoking intervention: randomized factorial trial. J Med Internet Res. 2013;15(3):e69. http:

//dx.doi.org/10.2196/jmir.2508.

32. Brindal E, Freyne J, Saunders I, et al. Features predicting weight loss in overweight or obese participants in a web-based intervention: random- ized trial. $J$ Med Internet Res. 2012;14(6):e173. http://dx.doi.org/ 10.2196/jmir.2156.

33. Morrison L, Hargood C, Lin SX, et al. Understanding usage of a hybrid website and smartphone app for weight management: a mixed- methods study. J Med Internet Res. 2014;16(10):e201. http://dx.doi. org/10.2196/jmir.3579.

34. Murray E, Hekler EB, Andersson G, et al. Evaluating digital health interventions: key questions and approaches. Am J Prev Med. 2016.

35. Gonzalez VM, Dulin P. Comparison of a smartphone app for alcohol

use disorders with an Internet-based intervention plus bibliotherapy: a pilot study. $J$ Consult Clin Psychol. 2015;83(2):335-345. http://dx.doi. org/10.1037/a0038620.

36. Lippke S, Corbet JM, Lange D, Parschau L, Schwarzer R. Intervention engagement moderates the dose-response relationships in a dietary intervention. Dose Response. 2016;14(1). http://dx.doi.org/10.1177/ 1559325816637515.

37. Mohr DC, Schueller SM, Riley WT, et al. Trials of intervention

principles: evaluation methods for evolving behavioral intervention technologies. J Med Internet Res. 2015;17(7):e166. http://dx.doi.org/ 10.2196/jmir.4391.

38. Patrick K, Hekler EB, Estrin D, et al. Rapid rate of technological

development and its implications for research on digital behavior change interventions. Am J Prev Med. 2016.

39. Fairclough SH, Gilleade K, Ewing KC, Roberts J. Capturing user

engagement via psychophysiology: measures and mechanisms for biocybernetic adaptation. Int J Auton Adapt Commun Syst. 2013;6 (1):63. http://dx.doi.org/10.1504/IJAACS.2013.050694.

40. Crutzen R, Cyr D, Larios H, Ruiter RAC, de Vries NK. Social presence and

use of Internet-delivered interventions: a multi-method approach. PLoS One. 2013;8(2):e57067. http://dx.doi.org/10.1371/journal.pone.0057067.

41. Bradbury K, Dennison L, Little P, Yardley L. Using mixed methods to

develop and evaluate an online weight management intervention. $\mathrm{Br}$ J Health Psychol. 2015;20(1):45-55. http://dx.doi.org/10.1111/bjhp.12125.

42. van Gemert-Pijnen JE, Nijland N, van Limburg M, et al. A holistic

framework to improve the uptake and impact of eHealth technologies. 
J Med Internet Res. 2011;13(4):e111. http://dx.doi.org/10.2196/ jmir.1672.

43. Yardley L, Morrison L, Bradbury K, Muller I, Yardley L. The person-

based approach to intervention development: application to digital health-related behavior change interventions. J Med Internet Res. 2015;17(1): $\mathrm{e} 30$. http://dx.doi.org/10.2196/jmir.4055.

44. Vandelanotte C, Muller AM, Short CE, et al. Past, present and future of eHealth and mHealth research to improve physical activity and dietary behaviors. J Nutr Educ Behav. 2016;48(3):219-228. http://dx.doi.org/ 10.1016/j.neb.2015.12.006.

45. Mackert M, Champlin S, Holton A, Muñoz I, Damásio M. eHealth and health literacy: a research methodology review. $J$

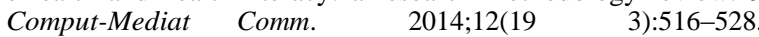
http://dx.doi.org/10.1111/jcc4.12044.

46. Barry M, D'Eath M, Sixsmith J. Interventions for improving population health literacy: insights from a rapid review of the evidence. $J$ Health Commun. 2013;18(12):1507-1522. http://dx.doi.org/10.1080/10810730. 2013.840699.

47. Glasgow R. Interactive media for diabetes self-management: issues in maximizing public health impact. Med Decis Making. 2010;30(6): http://dx.doi.org/10.1177/0272989X10385845.

48. Jacobs RJ, Lou JQ, Ownby RL, Caballero J. A systematic review of eHealth interventions to improve health literacy. Health Informatics $\quad$ J. 2016;22(2):81-98. http://dx.doi.org/10.1177/1460458214534092.

49. Rowsell A, Muller I, Murray E, et al. Views of people with high and low

levels of health literacy about a digital intervention to promote physical activity for diabetes: a qualitative study in five countries. $J$ Med Internet Res. 2015;17(10):e230. http://dx.doi.org/10.2196/jmir.4999.

50. Thomas JG, Bond DS. Behavioral response to a just-in-time adaptive intervention (JITAI) to reduce sedentary behavior in obese adults: implications for JITAI optimization. Health Psychol. 2015;34: 1261-1267. http://dx.doi.org/10.1037/hea0000304.

51. Riley WT, Serrano KJ, Nilsen W, Atienza AA. Mobile and wireless technologies in health behavior and the potential for intensively adaptive interventions. Curr Opin Psychol. 2015;5:67-71. http://dx. doi.org/10.1016/j.copsyc.2015.03.024.

52. Lustria MLA, Noar SM, Cortese J, et al. A meta-analysis of webdelivered tailored health behavior change interventions. $J$ Health $\begin{array}{lll}\text { Commun. } & \text { 2013;18 }\end{array}$ http://dx.doi.org/10.1080/10810730.2013.768727.

53. Deci EL, Ryan RM. Self-determination theory. In: Van Lange PAM,

Kruglanski AW, Higgins ET, eds. Handbook of Theories of Social Psychology. New York, NY: Elsevier; 2011:416-433.

54. Ryan RM, Deci EL. Self-determination theory and the facilitation of intrinsic motivation, social development, and well-being. $A m$ Psychol. 2000;55(1):68. http://dx.doi.org/10.1037/0003066X.55.1.68.

55. Kreuter MW, Strecher VJ, Glassman B. One size does not fit all: the case for tailoring print materials. Ann BehavMed. 1999;21(4):276283. http://dx.doi.org/10.1007/BF02895958.

56. Kreuter MW, Farrell DW, Olevitch LR, Brennan LK. Tailoring Health Messages: Customizing Communication With Computer Technology. New York: Routledge; 2013.

57. Baumeister H, Reichler L, Munzinger M, Lin J. The impact of guidance on Internet-based mental health interventions-a systematic review. Internet Interv. 2014;1(4):205-215. http://dx.doi.org/10.1016/j.invent. 2014.08.003.

58. Kleiboer A, Donker T, Seekles W, et al. Randomized controlled trial on the role of support in Internet-based problem solving therapy for depression and anxiety. Behav Res Ther. 2015;72:6371. http://dx.doi. org/10.1016/j.brat.2015.06.013.

59. Newman MG, Szkodny LE, Llera SJ, Przeworski A. A review of technology-assisted self-help and minimal contact therapies for anxiety and depression: is human contact necessary for therapeutic efficacy? Clin Psychol Rev. 2011;31(1):89-103. http://dx.doi.org/10.1016/j.cpr. 2010.09.008.

60. Riper H, Blankers M, Hadiwijaya H, et al. Effectiveness of guided and unguided low-intensity Internet interventions for adult alcohol misuse: 
a meta-analysis. PLoS One. 2014;9(6):e99912. http://dx.doi.org/10.1371/ journal.pone.0099912.

61. Zachariae R, Lyby MS, Ritterband LM, O'Toole MS. Efficacy of Internet-delivered cognitive-behavioral therapy for insomnia-a sys- tematic review and meta-analysis of randomized controlled trials. Sleep Med Rev. 2015;30:1-10. http://dx.doi.org/10.1016/j.smrv.2015.10.004.

62. Knowles S, Toms G, Sanders C, et al. Qualitative meta-synthesis of user

experience of computerized therapy for depression and anxiety. PLoS One. 2014;9(1):e84323. http://dx.doi.org/10.1371/journal.pone.0084323.

63. Santer M, Muller I, Yardley L, et al. Supporting self-care for families of

children with eczema with a web-based intervention plus health care professional support: pilot randomized controlled trial. J Med Internet Res. 2014;16(3):e70. http://dx.doi.org/10.2196/jmir.3035.

64. Mohr DC, Cuijpers P, Lehman K. Supportive accountability: a model for providing human support to enhance adherence to eHealth interventions. J Med Internet Res. 2011;13(1):e30. http://dx.doi.org/ 10.2196/jmir.1602.

65. van der Vaart R, Witting M, Riper H, et al. Blending online therapy into

regular face-to-face therapy for depression: content, ratio and precondi- tions according to patients and therapists using a Delphi study. BMC Psychiatry. 2014;14:355. http://dx.doi.org/10.1186/s12888-014-0355-z.

66. Smit ES, Hoving C, Cox VCM, de Vries H. Influence of recruitment

strategy on the reach and effect of a web-based multiple tailored smoking cessation intervention among Dutch adult smokers. Health Educ Res. 2012;27(1):191-199. http://dx.doi.org/10.1093/her/cyr099.

67. Spring B, Duncan JM, Janke EA, et al. Integrating technology into

standard weight loss treatment. JAMA Intern Med. 2013;173(2):105.

http://dx.doi.org/10.1001/jamainternmed.2013.1221. 